\title{
Odor-Evoked Oxygen Consumption by Action Potential and Synaptic Transmission in the Olfactory Bulb
}

\author{
Jérôme Lecoq, ${ }^{1,2,3}$ Pascale Tiret, ${ }^{1,2,3}$ Marion Najac, ${ }^{1,2,3}$ Gordon M. Shepherd, ${ }^{4}$ Charles A. Greer, ${ }^{5,6}$ and Serge Charpak ${ }^{1,2,3}$ \\ ${ }^{1}$ Institut National de la Santé et de la Recherche Médicale, U603, ${ }^{2}$ Centre National de la Recherche Scientifique, Unité Mixte de Recherche 8154, and \\ ${ }^{3}$ Laboratory of Neurophysiology and New Microscopies, Université Paris Descartes, Paris 75006, France, and Departments of ${ }^{4}$ Neurobiology, \\ ${ }^{5}$ Neurosurgery, and ${ }^{6}$ Neurobiology, Yale University School of Medicine, New Haven, Connecticut 06520
}

The relationship between metabolism of neuronal activity, microvascular organization, and blood flow dynamics is critical for interpreting functional brain imaging. Here we used the rat dorsal olfactory bulb as a model to determine in vivo the correlation between action potential propagation, synaptic transmission, oxygen consumption, and capillary density during odor stimulation. We find that capillary lumen occupies $\sim 3 \%$ of the glomerular volume, where synaptic transmission occurs, and only $0.1 \%$ of the overlying nerve layer. In glomeruli, odor triggers a local early decrease in tissue oxygen partial pressure that results principally from dendritic activation rather than from firing of axon terminals, transmitter release or astrocyte activation. In the nerve layer, action potential propagation does not generate local changes in tissue oxygen partial pressure. We conclude that capillary density is tightly correlated with the oxidative metabolism of synaptic transmission, and suggest that action potential propagation operates mainly anaerobically.

Key words: neurometabolic coupling; metabolism; oxygen; olfactory bulb; neurovascular coupling; odor

\section{Introduction}

The olfactory bulb $(\mathrm{OB})$ is a unique model for investigating in vivo the correlation between vascular density, synaptic transmission, metabolism, and neurovascular coupling (Shepherd and Charpak, 2008). Dorsal glomeruli can be easily imaged in vivo with two-photon laser-scanning microscopy (TPLSM), a technique that allows one to characterize vascular architecture with a micrometer spatial resolution, and to measure cerebral blood flow (CBF) and neuronal activity (Chaigneau et al., 2003, 2007) with a millisecond time resolution. The olfactory bulb has been well studied with respect to its synaptic organization (Shepherd et al., 2004). The superficial nerve layer is composed of glial cells and unmyelinated axons from olfactory sensory neurons (OSNs). The underlying layer is composed of glomerular modules in which OSN terminals synapse onto juxtaglomerular and principal cell dendrites. These two layers thus sharply differ in their cellular contents and can be expected to show differences in metabolism.

Studies investigating various aspects of metabolism in the two layers have reported contrasting results. 2-DG studies showed

Received 0ct. 7, 2008; revised Dec. 10, 2008; accepted Jan. 2, 2009.

This work was supported by the Institut National de la Santé et de la Recherche Médicale, the Ministère de I'Education Nationale de la Recherche et de la Technologie (NIC0025, ACI NIC0025, and ACI IBPC:DRAB 042492), the Centre National de la Recherche Scientifique, the Fondation pour la Recherche Médicale (ICP20001222128), the Région lle de France (Sesame program), the Fondation Bettancourt Schueller, the Human Frontier Science Program Organisation, and National Institutes of Health-National Institute for Deafness and Other Communicative Disorders (G.M.S., C.A.G.). Jérôme Lecoq was supported by a fellowship from the Fondation pour la Recherche Médicale (FDT20070910324) and Pascale Tiret by a fellowship from the Association Française contre les Myopathies (12411). We thank Etienne Audinat, Didier Desaintjan, and Janna Nawroth for their critical comments.

Correspondence should be addressed to Serge Charpak, Institut National de la Santé et de la Recherche Médicale U 603, Laboratory of Neurophysiology, 45 rue des St Pères, 75006 Paris, France. E-mail: serge.charpak@univ-paris5.fr.

DOl:10.1523/JNEUROSCI.4817-08.2009

Copyright $\odot 2009$ Society for Neuroscience $\quad 0270-6474 / 09 / 291424-10 \$ 15.00 / 0$ high energy demand in both glomeruli and the adjacent nerve layer (Sharp et al., 1975, 1977; Sokoloff et al., 1977; Greer et al., 1981). Early fMRI studies showed BOLD signals in both the glomerular and nerve layers (Yang et al., 1998; Xu et al., 2000; Kida et al., 2002). Higher-resolution fMRI studies confirmed the presence of BOLD signals in the nerve layer (Kida et al., 2002; Schafer et al., 2005). These results were in good accordance with theoretical calculations that show that ATP is almost equally consumed during action potential propagation and postsynaptic activation (Attwell and Laughlin, 2001). In contrast, the distribution of cytochrome $c$ oxidase, a key enzyme of oxidative metabolism, suggested that oxidative metabolism differs in the two layers: high levels of the enzyme were found in glomeruli (Borowsky and Collins, 1989; Hevner and Wong-Riley, 1989; Hevner et al., 1995) and little if any in the nerve layer. While measuring cerebral blood flow $(\mathrm{CBF})$ responses to odor in the glomerular layer, we observed that the nerve layer contained very few capillaries (Chaigneau et al., 2003) [see the comment by Shepherd (2003)]. Thus, the amount and the nature (i.e., through oxidative vs glycolytic metabolism) of the energy consumed in the nerve and glomerular layers, whether at rest or during sensory stimulation, remain unknown. It was only addressed theoretically (Nawroth et al., 2007) that, in glomeruli, the density of neuronal elements would be associated with a high resting energy consumption that increases upon firing of OSN axons and subsequent postsynaptic activation.

In the present study, we combined in vivo two-photon laserscanning microscopy (TPLSM) measurements of capillary density and CBF, polarographic measurements of oxygen (for review, see Ndubuizu and LaManna, 2007), and electrophysiological recording of local neuronal activity. We report that, upon odor stimulation, oxygen is principally consumed in glomeruli where capillary and 
mitochondria densities are very high and not in the nerve layer. Furthermore, glomerular oxygen consumption results mainly from dendritic activation rather than from firing of axon terminals, transmitter release, or astrocyte activation.

\section{Materials and Methods}

Animal preparation. Thirty-one Wistar rats (postnatal days 30-70) were used and anesthetized with either urethane (i.p., $1.65 \mathrm{~g} / \mathrm{kg}$ ) or ketamine and xylazine (i.p., $90 \mathrm{mg} / \mathrm{kg}$ and $10 \mathrm{mg} / \mathrm{kg}$, respectively) and held in a standard stereotaxic apparatus. Surgery was performed as previously described. The posterior cisterna was drained. A craniotomy was performed above the two olfactory bulb hemispheres and the dura was removed. A 100- $\mu \mathrm{m}$-thick glass coverslip was placed over the bulb and fixed on the cranium, and the space below was filled with a $3.25 \%$ agar solution. The temperature of the animal was monitored with a rectal thermometer and maintained at $37^{\circ} \mathrm{C}$ with a feedback-controlled heating blanket (Harvard Apparatus). In several experiments, we monitored breathing frequency through a pneumogram transducer (BIOPAC Systems). Occasionally blood $\mathrm{PO}_{2}, \mathrm{PCO}_{2}$, and $\mathrm{pH}$ were controlled using a RapidLAB 348 analyzer from Bayer.

Electrophysiological recordings and application of drugs. To record local field potential, a borosilicate micropipette was filled with a standard extracellular solution and $10 \mu \mathrm{M}$ Oregon Green. To record glomerular activity, previously labeled glomeruli were targeted through agar using the method described below. Electrophysiological signals recorded with a NeuroData amplifier (Cygnus Technology) were digitized and stored on a PC (Digidata 1200A, Clampex 9, Axon Instruments). Olfactory nerve stimulation were performed using a tungsten microelectrode (TM31A50, World Precision Instruments), which was targeted in the nerve layer $\sim 1 \mathrm{~mm}$ from the recorded glomerulus (Chaigneau et al., 2007). Stimulation protocol consisted of 3 trains of 4 pulses $(200 \mu \mathrm{s})$ at $40 \mathrm{~Hz}$. For local application of drugs, we used Alexa 594 at $13 \mu \mathrm{M}$ as a fluorophore to avoid blurring glomerular boundaries (labeled with Oregon Green) during pressure injection. Laser power was adjusted before injection to follow, as precisely as possible, the spatial diffusion of the fluorescent solution. Of course, the precise extent of drug effective region is impossible to determine since we are only monitoring the dye and not the drug diffusion. In addition, in vivo experiments require to apply drugs at high concentration, conditions that increase the risk of generating nonspecific actions of drugs. Micromolar concentrations of CNQX and NBQX have been reported to increase GABA release in cerebellum (Brickley et al., 2001) through an unknown mechanism that does not involve AMPA or kainate receptors. In our conditions (see also Chaigneau et al., 2007), we used low pressure and brief applications (30-120 s) of $250 \mu \mathrm{M}$ NBQX. The real concentration reaching synapses was certainly much lower, allowing rapid recovery and drug reapplication. Prolonged applications gave similar results (data not shown), were more difficult to wash, and for this reason were avoided. Because we have already demonstrated that $250 \mu \mathrm{M}$ NBQX blocks the local field potential (LFP) negativities that report EPSPs in mitral cells (Chaigneau et al., 2007), it is unlikely that our approach reveals a nonspecific enhancement of GABA release that could modulate oxygen consumption (Caesar et al., 2008)

Measurements of oxygen partial pressure $\left(P_{\text {tiss, } \mathrm{O} 2}\right)$. Recordings were made with a Clark-style polarographic oxygen sensor (Unisense). The oxygen sensor was polarized with respect to an $\mathrm{Ag} / \mathrm{AgCl}$ internal reference electrode at $-0.8 \mathrm{~V}$. The current between the two electrodes is linearly related to the partial pressure of oxygen in the vicinity of the sensor tip. We calibrated at $37^{\circ} \mathrm{C}$ each sensor before experiments, first in saline with $21 \%$ oxygen (air-saturated) and then in $0 \%$ oxygen (bubbled with nitrogen). In several experiments, we also compared the calibration before and after the experiment without noting any significant difference. Oxygen electrodes are known to have a slow response time (see supplemental Fig. 1, available at www.jneurosci.org as supplemental material). To correct for this delay and measure the true oxygen dynamics, we measured for each electrode, the impulse response before the experiment, by differentiating a step change in oxygen concentration: the electrode was rapidly moved from air to $0 \%$ oxygen saline. With the presence of fluorescein in the electrolyte, our electrodes showed an exponential decay time of $\sim 200 \mathrm{~ms}(\tau=209 \pm 98 \mathrm{~ms}, n=16$ electrodes $)$. We then divided in the Fourier domain the impulse response of the sensor. To avoid high-frequency noise generated by this process, both the impulse response and resulting signal were low-pass filtered (respectively with 5 $\mathrm{Hz}$ and $1.5 \mathrm{~Hz}$ cutoff, Butterworth filter, order 4, applied both forward and backward to allow zero-phase delay). This process simply shifted back in time the curves $(\sim 0.25 \mathrm{~s})$ and corrected the oxygen spectrum density to its true low frequency value (supplemental Fig. $1 C$, available at www.jneurosci.org as supplemental material). All analyses were done on deconvolved oxygen responses. We did not characterize ourselves the volume of tissue detected by the electrode. However, according to the manufacturer (Unisense), the steady-state sensing region is a spherical region with a diameter twice that of the tip membrane $(1-3 \mu \mathrm{m})$, the non-steady-state region being theoretically smaller (Gundersen et al., 1998). Moreover, these electrodes consume a negligible amount of oxygen $\left(10^{-16} \mathrm{~mol}\right.$ of oxygen per second) compared with oxygen basal consumption in glomeruli (Nawroth et al., 2007).

In vivo two-photon imaging and targeting pipettes. Axon terminals from the olfactory nerve (and thus glomeruli) were labeled with Oregon Green dextran (MW 10,000) 2-8 d before experiments by using the methods developed by Wachowiak and Cohen (2001). To label vessels, a bolus of $70 \mathrm{kDa}$ Texas Red dextran was injected intravenously through a catheter placed in the femoral vein. We imaged the two fluorophores using a custom-built two-photon laser-scanning microscope with a 890 $\mathrm{nm}$ excitation beam as previously described (Chaigneau et al., 2007). In the rat, glomerular diameter may occasionally be as small as $40 \mu \mathrm{m}$. It is thus crucial to precisely control, in three dimensions (3D), the recording sites of both oxygen partial pressure and neuronal activity. Therefore, we did not use oxygen sensors with a fixed distance between the oxygen sensor and the local field potential electrode (Thompson et al., 2003, 2005; Offenhauser et al., 2005). Instead, we used a custom-built technique that enabled us to target pipettes in depth using two-photon imaging. In brief, the principle was to acquire $x, y$, and $z$ positions for one point, in the imaging coordinate system, and to convert it mathematically into the micromanipulator coordinate system. It was then possible to directly position two electrode tips in very close proximity. In our experiments, the distance between the two sensors tips ranged from 6 to $83 \mu \mathrm{m}$ (the latter in a large glomerulus), ensuring that both electrodes reported signals related to the same neuronal population.

$R B C$ velocity analysis. Line scans were acquired along the longitudinal capillary axis. Unlabeled RBCs appeared as tilted dark shadows on a bright fluorescent plasma background. The values of the velocities were calculated using algorithms based on (Kleinfeld et al., 1998). The velocities of the RBCs were inversely proportional to the tangent of the shadow angle. Images were pretreated using $5 \times 5$ median and low-pass filters and subdivided into brief images $I(n)$ of $100-200 \mathrm{~ms}$ duration. The average velocity $v(n)$ of RBCs in $I(n)$ was then calculated as follows: (1) each image $I(n)$ was rotated by an incremental angle $\alpha$, (2) a singular value decomposition was performed on each rotated image, (3) the $\alpha$ value for which we obtained the greatest first singular value provided the average angle of the RBC shadow in $I(n)$, and $(4) v(n)$ was calculated as $v(n)=$ $1 / \tan (\alpha)$. The onset of the vascular response was defined as the moment when two successive values were larger than twice the resting velocity SD.

$3 D$ vascular anatomy extraction. To characterize the $3 \mathrm{D}$ vascular architecture from image stacks of labeled vessels, we used a modified version of the Fast-Marching Algorithm (Sethian, 1999), adapted from Deschamps and Cohen (2001). The principle of the algorithm was to use a stack of images as a material into which virtual waves could be propagated. As long as these waves respected some of the mathematical properties of electromagnetic waves, their path indicated information on the structure located into the stack. The algorithm was composed of several steps described as follows and illustrated in supplemental Figure 2 (available at www.jneurosci.org as supplemental material). A starting point was manually chosen in the stack to initiate several waves (Fast-Marching algorithm). A first propagation used a function of gray level as refractive index to create a map of the "energy cost" to propagate from any point to the starting point (see supplemental Fig. $2 B$, available at www.jneurosci. org as supplemental material). Since it propagated faster along the white 
pixels (i.e., inside the vessels), the wave took the shape of the vessels connected to the starting point. One of the mathematical properties of this cost map relates to wave propagation theory, notably with its gradient always pointing in the direction of the shortest path to reach the starting point. Therefore, it was already possible to extract the vessel paths using a gradient descent algorithm. However, these paths did not follow the exact center of the vessels since the energy cost to propagate along the border and in the middle of the vessel was the same. To circumvent this problem, we created a new stack from the previous set of propagated points where pixels located in the center of the vessels propagated faster (see supplemental Fig. 2C, available at www.jneurosci.org as supplemental material). We therefore obtained a new cost map from which it was possible to extract proper vessel paths (see supplemental Fig. $2 D, E$, available at www.jneurosci.org as supplemental material). This allowed us to measure the radius of the vessels along the paths radius using a simple local edge detection algorithm (see supplemental Fig. $2 \mathrm{~F}$, available at www.jneurosci.org as supplemental material). Note that one of the main difference with (Deschamps and Cohen, 2001) relates to TPLSM specificities. Indeed, TPLSM resolution is higher along the $x$ - and $y$-axes than in the $z$ direction, in contrary to MRI voxels. To solve this problem, we recentered all the paths along the $z$-axis using the radius profile of the vessels along the $z$ direction.

To measure the average distance from any point of brain tissue to the nearest cerebral vessel, we extracted from 3D vascular reconstructions the distance from each voxel to the nearest intravascular wall. Calculations of the average distance imposed to fix the voxel values in the lumen of vessels to zero. To average several glomerular columns, we took into account the shape of each glomerulus, which was reconstructed in $3 \mathrm{D}$ and morphed into a sphere of equivalent volume. To average several columns, 3D distance maps were similarly morphed: each 3D columnar distance map was first averaged on a plane rotating around the central axis of the column. The obtained 2D distance maps were then averaged and normalized by each glomerular radius (see Fig. 1). Note that labeled olfactory nerve terminals outline only the glomerular boundaries. Therefore, in our calculations the periglomerular region was artificially contained in both the ONL and the EPL. We preferred this approach to the subtraction of an unknown thickness assigned to the periglomerular region.

Electron microscopy protocol. Sprague Dawley rats, 60-120 d postnatal, were perfused through the heart with $\mathrm{PBS}$ at $4^{\circ} \mathrm{C}$ followed by $4 \%$ paraformaldehyde and $1 \%$ glutaraldehyde in PBS. The treatment of the animals was approved by the Yale Institutional Animal Care and Use Committee. The olfactory bulbs were removed, postfixed overnight in the perfusate at $4^{\circ} \mathrm{C}$, and $100 \mu \mathrm{m}$ sections were cut on the Vibratome. Further processing largely followed our established protocols [i.e., Kasowski et al. (1999)]. The $100 \mu \mathrm{m}$ sections were washed three times for $10 \mathrm{~min}$ each with PBS and then osmicated with $2 \%$ osmium tetrachloride for $1 \mathrm{~h}$. After a series of graded alcohol washes with $50 \%$ ethanol (EtOH) for 10 min and 70\% EtOH for $10 \mathrm{~min}$, they were stained en bloc with $1 \%$ uranyl acetate in $70 \% \mathrm{EtOH}$ for $1 \mathrm{~h}$. The sections were further rinsed with $70 \%$ EtOH for $10 \mathrm{~min}, 90 \% \mathrm{EtOH}$ for $20 \mathrm{~min}$, and $100 \% \mathrm{EtOH}$ three times for $15 \mathrm{~min}$ each. Next, they were rinsed twice with propylene oxide for $5 \mathrm{~min}$ each. The sections were then put in a 1:1 propylene oxide/Epon 812 (Epon) mixture on a shaker overnight. The following day, the sections were infiltrated with fresh Epon for $2 \mathrm{~h}$, flat embedded in fresh Epon onto quick-release-coated slides (Hobby Time Mold Parting Compound; Electron Microscopy Sciences), coverslipped with quick-release-coated coverslips, and polymerized in a $60^{\circ} \mathrm{C}$ oven overnight. Slides were examined with a light microscope, and areas of the Epon film containing $\mathrm{OB}$ tissue with a good stretch of intact ONL were cut out and remounted on Epon blocks and polymerized for $48 \mathrm{~h}$ before thin sectioning. Silver sections $(70-100 \mathrm{~nm})$ were cut with a Reichert-Jung ultramicrotome, and mounted on slotted grids $(2 \mathrm{~mm} \times 1 \mathrm{~mm})$ covered with Formvar $(0.5 \%$ in ethylene dichloride). The grids were poststained with $1 \%$ lead citrate for $1.5 \mathrm{~min}$, and examined using a JEOL 1200 EXII $120 \mathrm{kV}$ transmission electron microscope.

Electron micrographs were captured at a primary magnification of $10,000 \times$, which provided a working magnification of $24,000 \times$ after printing. From electron micrographs of the olfactory nerve layer totaling
$19,375 \mu \mathrm{m}^{2}$, we randomly sampled $1500 \mu \mathrm{m}^{2}$ using a template with a $2 \times 5 \mu \mathrm{m}$ window. From electron micrographs of the glomerular neuropil totaling $16,300 \mu \mathrm{m}^{2}$, we randomly sampled $1500 \mu \mathrm{m}^{2}$ using the same template. Within the template window, all mitochondria were counted. Surfaces of mitochondria were quantified as follows: $\Pi \times$ (radius $)^{2}$ for spherical mitochondria and length major axis $\times$ length $_{\text {minor axis }}$ for elongated mitochondria.

Data analysis. All data were analyzed through a home-made MATLAB program (MathWorks). 3D Vascular anatomy extraction was partially programmed in $\mathrm{C}++$ to minimize computation time. RBCs flow extraction was performed in LABVIEW (National Instruments). In the entire study, average values are expressed as mean \pm SEM.

\section{Results}

\section{Quantification of capillary density in the nerve and glomerular layers of the dorsal OB}

Using TPLSM and selected volumes in the olfactory nerve and glomerular layers, we have previously shown, in vivo, that the capillary network was denser in the glomerular than in the nerve layer (Chaigneau et al., 2003). In another study performed in slices of fixed tissue, Borowsky and Collins (1989) reported that the network of small blood vessels $(<10 \mu \mathrm{m})$ was denser in the GL than in the external plexiform layer. None of these studies precisely quantified, in millimeters per cubic millimeter, the density of capillaries in the two superficial layers, a requirement to compare values with those of other brain regions. We thus developed a new 3D algorithm based on a modified version of the Fast-Marching Algorithm (Sethian, 1999) (see Materials and Methods and supplemental Fig. 2, available at www.jneurosci.org as supplemental material) to reconstruct the entire vascular structure irrigating the OB layers. The algorithm was able to automatically compute the complete path, radius, and angle of all vessels labeled with Texas Red and located in TPLSM stacks. Figure 1 illustrates a typical volume of the $\mathrm{OB}$, fully reconstructed.

In glomeruli, the mean capillary density (diameter $<6 \mu \mathrm{m}$ ) was extremely high $\left(1056 \pm 72 \mathrm{~mm} / \mathrm{mm}^{3}, n=7\right.$ glomerular columns), the capillary lumen thus filling up to $\sim 2.98 \%$ of the glomerular volume. Increasing the diameter threshold to $10 \mu \mathrm{m}$ only slightly increased the glomerular capillary density (1137 \pm $61 \mathrm{~mm} / \mathrm{mm}^{3}$ ). Because the vast majority of glomerular vessels had a diameter $<6 \mu \mathrm{m}$ in our experimental conditions (urethane anesthesia), we propose that they correspond to true capillaries while vessels with diameter between 6 and $10 \mu \mathrm{m}$ already include small arterioles. Within glomeruli, capillary density was homogenous (upper half sphere density $=1139 \pm 130 \mathrm{~mm} / \mathrm{mm}^{3}$, lower half sphere density $\left.=960 \pm 80 \mathrm{~mm} / \mathrm{mm}^{3}, p=0.3\right)$. As a consequence of the high capillary density, the average distance of any point to the nearest capillary $(<6 \mu \mathrm{m})$ internal border was $10.78 \pm 0.73 \mu \mathrm{m}$ (Fig. $1 E$, left). This value decreased to $9.96 \pm$ $0.51 \mu \mathrm{m}$ when including all vessels (Fig. $1 E$, right).

In the nerve layer the mean capillary density was extremely low ( $45 \pm 26 \mathrm{~mm} / \mathrm{mm}^{3}, n=7$ glomerular columns), the capillary lumen filling up $\sim 0.12 \%$ of the glomerular volume. The density remained low when the capillary diameter threshold was raised to $10 \mu \mathrm{m}\left(90 \pm 54 \mathrm{~mm} / \mathrm{mm}^{3}\right)$. In fact, the overall "large" $(>10 \mu \mathrm{m})$ vessel density was low in the nerve layer $\left(52 \pm 28 \mathrm{~mm} / \mathrm{mm}^{3}\right)$. In this layer and for a point located at one glomerular radius above the glomerular border, the average distance to the nearest capillary internal border was $36.55 \pm 1.69 \mu \mathrm{m}$. This value decreased to $27.97 \pm 4.63 \mu \mathrm{m}$ when including all vessels.

Altogether, our vessels' quantification indicates that in the dorsal $\mathrm{OB}$, the glomerular capillary density is one of the highest reported in the brain and confirm that the nerve layer is almost devoid of capillaries (Chaigneau et al., 2003). Note that the cap- 
A

3D reconstruction of vessels and glomeruli

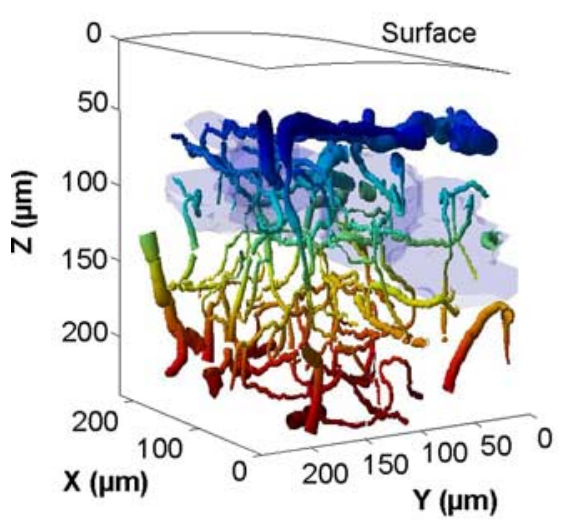

B
Single extracted glomerular column

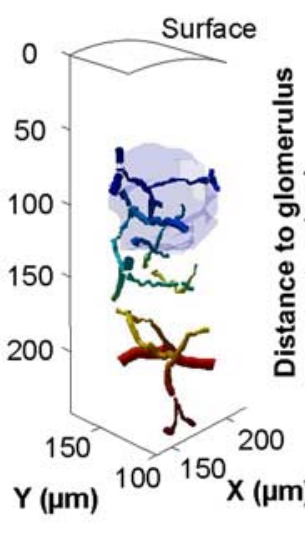

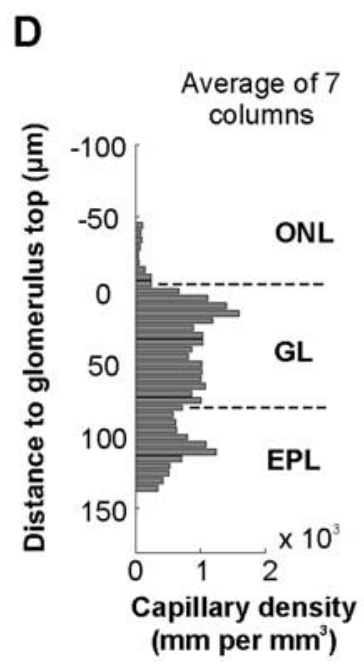
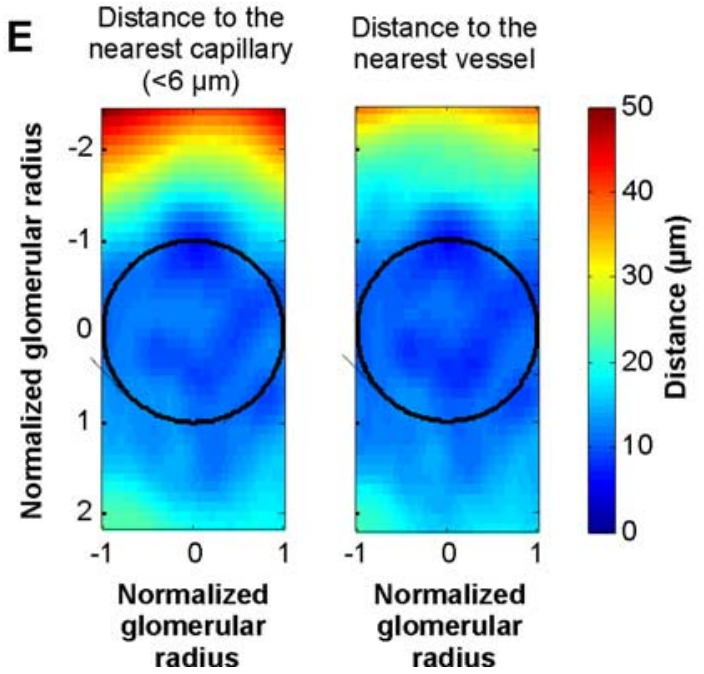

Figure 1. Quantification of capillary density in the olfactory bulb superficial layers. Vessels and glomeruli were reconstructed in 3D from stacks of images obtained with TPLSM in vivo and using an original reconstruction algorithm. Glomeruli were labeled with Oregon Green dextran and vessels with Texas Red. Vessel colors vary with depth. Glomeruli are indicated in light blue. B, Each glomerular column can be extracted from the reconstructed olfactory bulb volume. C, Capillary density [total length of vessels (diameter $<6 \mu \mathrm{m}$ ) per unit of volume] as a function of depth. Densities were obtained from the four glomerular columns extracted from A.D. Average of capillary densities from seven glomerular columns. Note that few capillaries if any were present in the olfactory nerve layer (ONL) compared with the glomerular layer (GL) where the density is extremely high. $\boldsymbol{E}$, Average distance from any point of a glomerular column to the nearest capillary (left) or vessel (right) internal border. Data were calculated from the previous glomerular columns (D) (see Materials and Methods). The color lookup table indicates the distance in micrometers.

illary density in the external plexiform layer (diameter $<6 \mu \mathrm{m}$; $746 \pm 111 \mathrm{~mm} / \mathrm{mm}^{3}, n=7$ glomerular columns) was significantly lower than in the GL ( $p=0.0017)$ and significantly higher than in the ONL $(p=0.0015)$. This contrasting vessel distribution suggests that tissue oxygen partial pressure $\left(\mathrm{P}_{\text {tiss, } \mathrm{O} 2}\right)$ could differ in the ONL and the GL whether at rest or during sensory stimulation.

\section{Steady-state $P_{\text {tiss, } O 2}$ in the nerve and glomerular layers}

In a recent work (Chaigneau et al., 2007), we have shown that we can target fluorescent extracellular recording pipettes in various layers of the rat olfactory bulb. Here, we used a modified version of a "Clark-like" polarographic oxygen sensor that was filled with fluorescein. This enabled us to place the oxygen sensor under TPLSM visual control at various depths and sites in the olfactory bulb In all experiments ( $n=30$ rats), the delays between measured and true $\mathrm{P}_{\text {tiss, } \mathrm{O} 2}$ measurements were corrected by decon-
C

4 glomerular columns

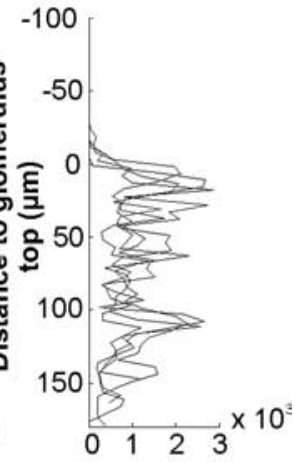
( $\mathrm{mm}$ per $\mathrm{mm}^{3}$ )
Capillary density

volving the impulse response function of each sensor from the signal measured in vivo (see Materials and Methods and supplemental Fig. 1, available at www.jneurosci. org as supplemental material). Considering the diameter of the tip membrane (1-3 $\mu \mathrm{m})$, the steady-state sensing region should be a spherical region with a diameter of $\sim 2-6 \mu \mathrm{m}$ (Gundersen et al., 1998). Removing the oxygen sensor from the center of glomeruli to sites in the periglomerular region and above, in the nerve layer (Fig. 2), revealed that resting $\mathrm{P}_{\text {tiss, } \mathrm{O} 2}$ was maintained in all layers $\left(\mathrm{P}_{\text {tiss, }, \mathrm{O} 2}\right.$ in glomeruli $=25.4 \pm 2.9 \mathrm{mmHg} ; \mathrm{P}_{\text {tiss }, \mathrm{O} 2}$ in the nerve layer $=27.1 \pm 4.2 \mathrm{mmHg}, p=0.36$, $n=5$, paired Student's $t$ test). A significant portion of oxygen is known to diffuse radially from arteriolar vessel segments (Tsai et al., 1998, 2003). However, the near absence of capillaries or of any vessels in the nerve layer along with the observation that resting $\mathrm{P}_{\text {tiss, } \mathrm{O} 2}$ was similar in both layers suggest that in the steady state, oxygen diffusion from glomerular capillaries participates to $\mathrm{P}_{\text {tiss, } \mathrm{O} 2}$ in the nerve layer.

\section{Odor-evoked $\mathrm{P}_{\text {tiss, } \mathrm{O} 2}$ changes in glomeruli}

We have recently characterized a component of LFP responses to odor that is generated locally, within a glomerulus (Chaigneau et al., 2007): it consists of respiration-locked rapid negativities that involve mitral cell dendritic synaptic depolarization and are extremely similar within glomerular boundaries. LFP and oxygen electrodes were targeted in the same glomerulus and thus reported signals related to the same neuronal population. The distance between the two sensor tips ranged from 6 to $83 \mu \mathrm{m}$ (the latter in a large glomerulus). Two types of oxygen responses were observed: the first one (Fig. $3 B$ ) was characterized by a LFP response rapidly ( $\sim 100 \mathrm{~ms})$ followed by a decrease in $\mathrm{P}_{\text {tiss, } \mathrm{O} 2}$ (oxygen "initial dip") and the second one (Fig. $3 \mathrm{C}$ ) by a LFP response associated with a biphasic change in $\mathrm{P}_{\text {tiss, } \mathrm{O} 2}$ (a decrease followed by an increase). Both types of response were followed by an increase in CBF. On average, LFP responses preceded oxygen negativities by $\sim 0.17 \mathrm{~s}( \pm 0.02 \mathrm{~s} ; n=14)$ and blood flow responses by $\sim 1.91 \mathrm{~s}( \pm 0.12 \mathrm{~s} ; n=9)$. The onset of $\mathrm{P}_{\text {tiss, } \mathrm{O} 2}$ responses was determined as the intersection between a straight line fitted on resting values and the initial slope of $\mathrm{P}_{\text {tiss, } \mathrm{O} 2}$ negativities fitted with a straight line drawn between 10 and $200 \mathrm{~ms}$ of the response. The two types of $\mathrm{P}_{\text {tiss, } \mathrm{O} 2}$ responses are reminiscent of what has been observed in the cortex (Thompson et al., 2003) and the lateral geniculate nucleus (LGN) (Thompson et al., 2004, 2005) where small grating stimuli elicited monophasic responses and large stimuli, involving larger portions of the LGN, evoked biphasic responses. The functional organization of the $\mathrm{OB}$ suggests that "specific" odor stimulations activating one to few glomeruli (Chaigneau et al., 2003; Petzold et al., 2008) elicit 
A

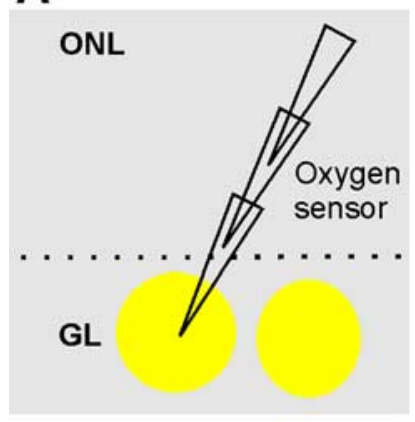

B

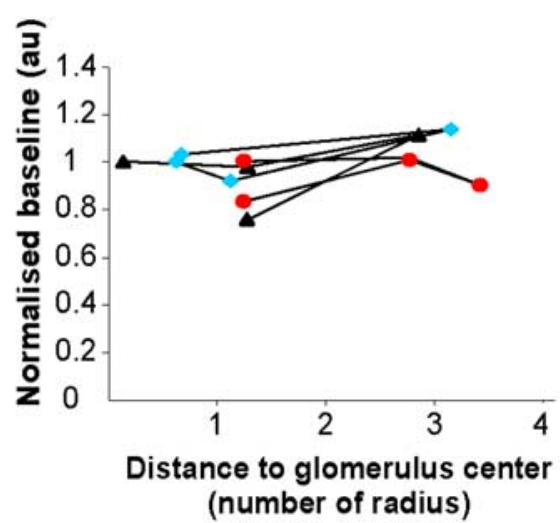

C

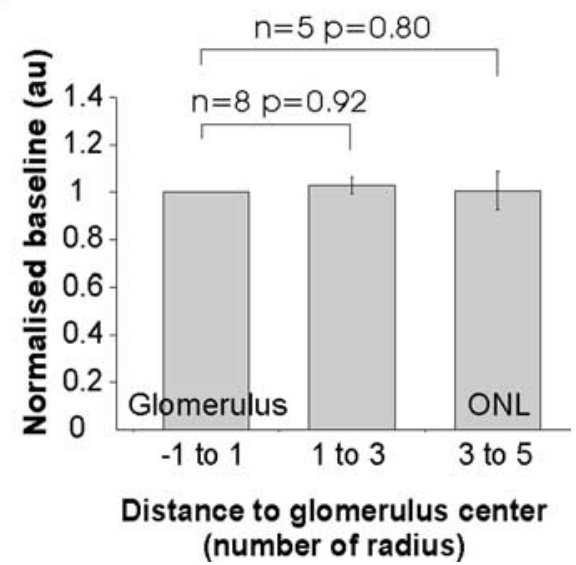

Figure 2. Resting $P_{\text {tiss, } 02}$ in the $0 N L$ and GL. $A$, Schematics. A fluorescent oxygen electrode (fluorescein) was placed at several sites in the $G L$ and $0 N L$. $B$, $P_{\text {tiss, } 02}$ (normalized to the $G L$ value) as a function of distance from the glomerular center. Each value is an average of three to six measurements. Note that moving the electrode back and forth ( $n=3$ rats) may slightly affect the oxygen measurements. The symbols indicate different experiments. $\boldsymbol{C}$, At resting state, $\mathrm{P}_{\text {tiss }, 02}$ is similar in both the $\mathrm{GL}$ and the $0 \mathrm{NL}$.

monophasic $\mathrm{P}_{\text {tiss, } \mathrm{O} 2}$ responses while strong odor responses activating several glomeruli (Chaigneau et al., 2007), i.e., a large network of vessels, trigger biphasic responses. However, at the level of a single glomerular capillary, both responses evoke a similar delayed increase in CBF. Still, it is important to note that even the apparent "pure" decrease in $\mathrm{P}_{\text {tiss, } \mathrm{O} 2}$ in Figure $3 B$ was also shaped by the delayed CBF increase as it has been shown in the cerebellum (Offenhauser et al., 2005): There, inhibition of nitric oxide synthase blocked CBF responses and uncovered the whole $\mathrm{P}_{\text {tiss, } \mathrm{O} 2}$ change evoked by climbing fiber stimulation. To eliminate the influence of $\mathrm{CBF}$ in both mono and biphasic $\mathrm{P}_{\text {tiss, } \mathrm{O} 2}$ responses, we only considered the initial slope of $\mathrm{P}_{\text {tiss, } \mathrm{O} 2}$ decreases in quantifying $\mathrm{P}_{\text {tiss, } \mathrm{O} 2}$ changes. This initial slope can be considered as a marker of local oxygen consumption, at least at the onset of the response to a stimulation (see discussion). Its average value was $-2.86 \pm 0.12 \mathrm{mmHg} / \mathrm{s}(n=8)$. Note that moving the sensor by $\sim 10 \mu \mathrm{m}$ within glomerular boundaries did not affect the initial slope of $\mathrm{P}_{\text {tiss, } \mathrm{O} 2}$ changes. As expected, LFP and $\mathrm{P}_{\text {tiss, } \mathrm{O} 2}$ responses increased with odor concentration (Fig. $3 D, E$ ).

\section{Role of spontaneous and odor-evoked activity in glomerular $\mathbf{P}_{\text {tiss, }}$ 2}

To discriminate the role of presynaptic versus postsynaptic compartments on $\mathrm{P}_{\text {tiss,O2, }}$, we repeated our experiments after focal injections of antagonists of glutamate ionotropic receptors. The effects of such drugs in vivo are complex: they block odor-evoked LFP responses (Chaigneau et al., 2007). However, they also enhance OSN presynaptic calcium signals evoked by odors, an effect related to a blockade of tonic presynaptic inhibition (Petzold et al., 2008; Pírez and Wachowiak, 2008). Therefore at rest, a tonic excitatory input onto inhibitory cells causes GABA release and tonic activation of GABAB receptors located on OSN terminals. By blocking this tonic inhibition, glutamate antagonists increase the amount of glutamate released from OSN terminals but also decrease dendritic glutamate and GABA release. Using the same patch pipette to apply antagonists of glutamate ionotropic receptors $(250 \mu \mathrm{M}$ NBQX and $500 \mu \mathrm{M} \mathrm{D}-\mathrm{APV}$, see experimental procedures on the use of high concentration of drugs) and measure LFP responses (Fig. 4), we observed that intraglomerular blockade of synaptic transmission did not affect resting $\mathrm{P}_{\text {tiss,O2 }}\left(\mathrm{P}_{\text {tiss,O2 }}\right.$ in control $=22.9 \pm 4.0 \mathrm{mmHg} ; \mathrm{P}_{\text {tiss, } \mathrm{O} 2}$ with antagonists $=25.8 \pm$ $5.3 \mathrm{mmHg}, p=0.15, n=6)$. This indicates that a glomerulus in two very different "states" of spontaneous activity, i.e., at rest and in a condition where the tonic excitatory drive of glomeruli is abolished and CBF remains constant (Petzold et al., 2008), can consume the same amount of oxygen.

In contrast, glutamate antagonists strongly decreased both LFP responses [note the disappearance of the locally generated negativities locked to respiration (Chaigneau et al., 2007)] and the initial slope of $\mathrm{P}_{\text {tiss }, \mathrm{O} 2}$ changes. The fact that $\mathrm{P}_{\text {tiss }, \mathrm{O} 2}$ changes were largely ( $16 \%$ of control) if not totally blocked, while glutamate release by OSN terminals was enhanced (Pírez and Wachowiak, 2008), suggests that oxygen consumption resulted principally from the activation of glomerular postsynaptic processes, and among those from dendrites and not from astrocyte processes (see discussion). Furthermore, considering that the olfactory receptor terminal compartment occupies an extremely large portion $(30 \%)$ of the glomerular volume (Nawroth et al., 2007), our data are really surprising: restoration of the ionic gradient for such a large glomerular portion should cost energy. Therefore our results suggest that either very few axons fire upon odor stimulation or that the energy required to fire axons and release glutamate may partially operate on an anaerobic metabolism.

\section{Comparison of odor-evoked $\mathrm{P}_{\text {tiss, } \mathrm{O} 2}$ changes in glomerular and nerve layers}

In their brain energy budget, Attwell and Laughlin (2001) estimated that a significant part of ATP is consumed by action potential propagation. Therefore, and in particular in the absence of capillaries, large $\mathrm{P}_{\text {tiss, } \mathrm{O} 2}$ changes could be expected when ORN unmyelinated axons fire in the nerve layer. We first placed the oxygen sensor and the LFP electrode in a glomerulus and recorded odor responses. We then moved the oxygen sensor in the adjacent juxtaglomerular and nerve layers (Fig. 5A) while the LFP electrode was maintained at its primary location to ensure that neuronal responses remained constant (Fig. 5B, gray traces). $\mathrm{P}_{\text {tiss,O2 }}$ measurements were performed back and forth between glomerular and nerve layer sites, allowing us to ascertain that $\mathrm{P}_{\text {tiss,O2 }}$ changes where independent of whether measurements were first done in the nerve or in the glomerular layer. $\mathrm{P}_{\text {tiss, } \mathrm{O} 2}$ changes were significantly smaller in the nerve layer (normalized initial slope $=28 \pm 6.2 \%, p=0.0003, n=5$ ) than in glomeruli (Fig. 5C). In addition, the delay between LFP responses and the 
A

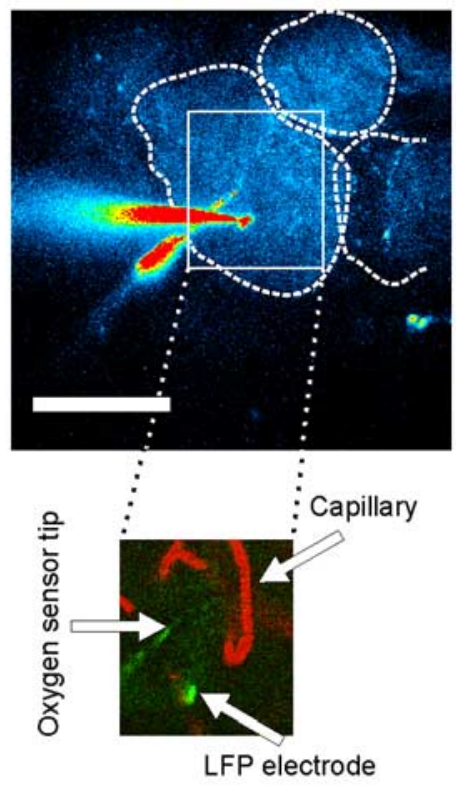

D

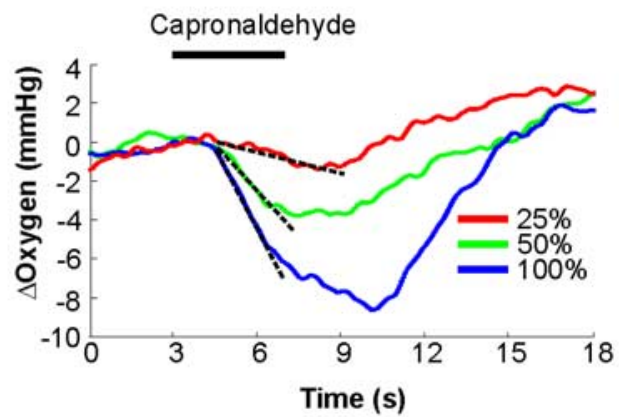

B
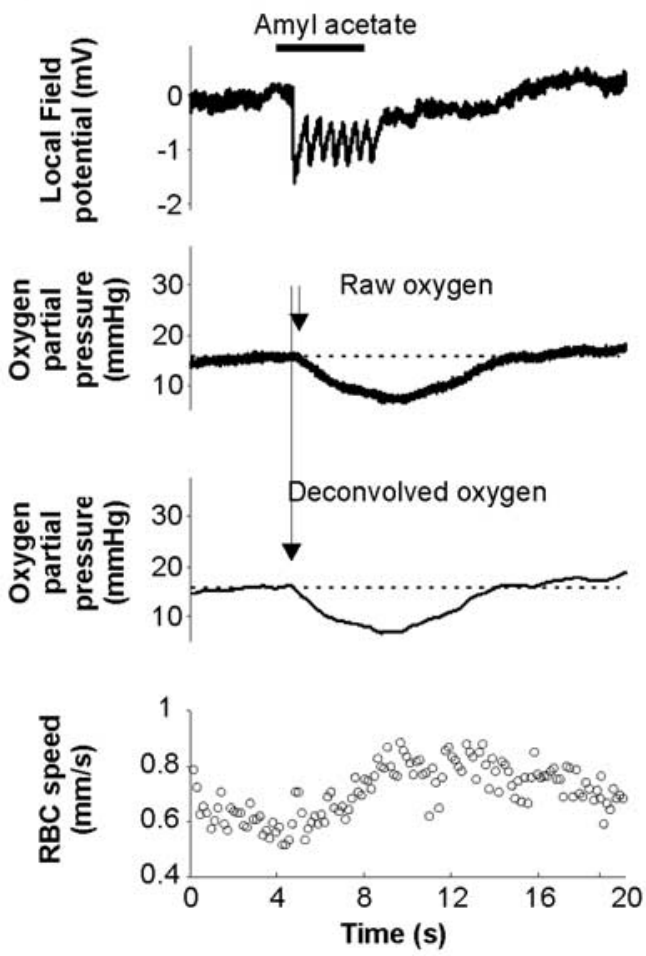

C
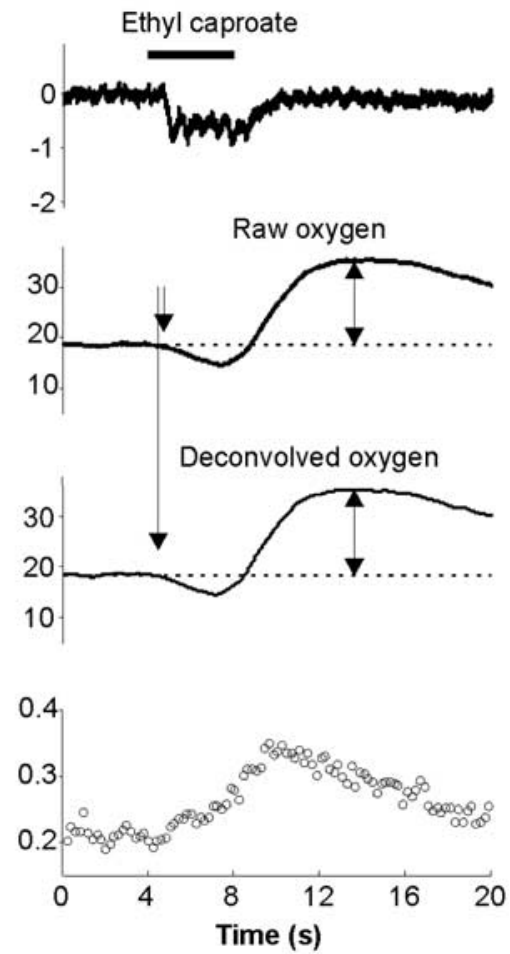

E

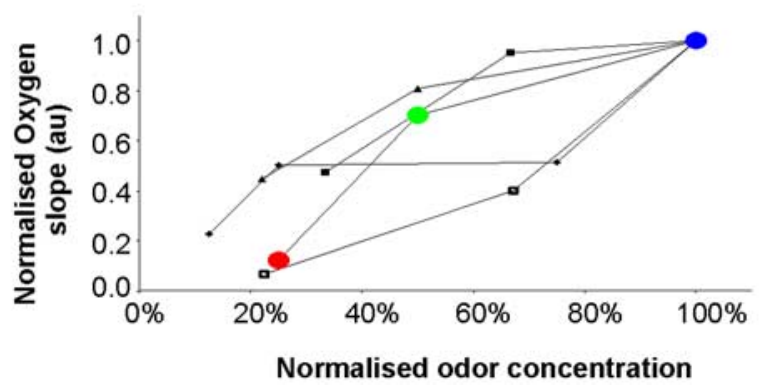

Figure 3. $\mathrm{P}_{\text {tiss }, 02}$ responses to odor. $A$, Top, A labeled (Oregon Green dextran) glomerulus was targeted with a fluorescein-containing oxygen sensor and an LFP electrode (Oregon Green). Scale bar, $100 \mu \mathrm{m}$. Bottom, Capillaries injected with Texas Red were imaged near both electrode tips allowing us to record simultaneously cerebral blood flow (CBF), LFP, and $P_{\text {tiss }, 02}$ responses to odor. $B$, A case where odor evoked an LFP response that was followed by a rapid initial oxygen negativity and a delayed RBC flow increase. Note that deconvolving $P_{\text {tiss, } 02}$ measurement for the slow impulse response of the oxygen electrode shifts the trace to the left. $C$, Another case where odor evoked a biphasic $P_{\text {tiss }, 02}$ signal, a rapid initial oxygen dip and a positive rebound that follows the delayed $C B F$ increase. $\boldsymbol{D}, \boldsymbol{E}, 0$ dor and $\mathrm{P}_{\text {tiss }, 02}$ responses are concentration dependent. To quantify $P_{\text {tiss, } 02}$ responses, the initial slope value of oxygen negativities was used. The symbols indicate different experiments. Rounds indicate the values obtained in $\boldsymbol{D}$.

onset of $\mathrm{P}_{\text {tiss, } \mathrm{O} 2}$ negativities increased (Fig. 5D) with distance from the glomerular upper limit (see also the arrow in Fig. $5 B$ ). This delay could indicate that $\mathrm{P}_{\text {tiss, } \mathrm{O} 2}$ changes recorded in the nerve layer indirectly report glomerular $\mathrm{P}_{\text {tiss, } \mathrm{O} 2}$ changes delayed by diffusion. However, two other possibilities should be considered, in particular in the ideal condition where an odor activates a single glomerulus: (1) the delay measured in the nerve layer was not correctly determined because $\mathrm{P}_{\text {tiss, } \mathrm{O} 2}$ negativities were too small, because few axons fire upon odor; and (2) due to the functional organization of the nerve layer, the $\sim 10,000$ axons conveying the information of OSNs expressing the same odorant molecule form small fascicles that converge from several directions in their glomerulus (Kasowski et al., 1999). Thus, by removing the oxygen sensor from the glomerulus in the nerve layer, it was misplaced at a distance from activated axons, inducing a diffusion delay in $\mathrm{P}_{\text {tiss, } \mathrm{O} 2}$ measurements.
To circumvent this problem, we modified the stimulation protocol and increased the ratio of axons activated in the nerve layer per axon terminals activated within a given glomerulus. Strong electrical stimulations [ 3 trains of 4 pulses $(100 \mu \mathrm{s})$ at 40 $\mathrm{Hz},>1 \mathrm{~mA}]$ were applied through a monopolar tungsten electrode placed in the nerve layer. The oxygen sensor was placed either in the nerve layer (between the stimulation electrode and a targeted glomerulus) or in a glomerulus. For a glomerular $\mathrm{P}_{\text {tiss, } \mathrm{O} 2}$ response of similar amplitude to one evoked by odor, such electrical stimulation is likely to activate a higher proportion of axons in the nerve layer: those projecting to the recorded glomerulus plus those converging to other glomeruli (Fig. $5 E$ ). As expected, electrical stimulation evoked $\mathrm{P}_{\text {tiss, } \mathrm{O} 2}$ were still smaller in the nerve layer than in glomeruli (nerve layer $=0.98 \pm 0.08 \mathrm{mmHg} / \mathrm{s}$; glomeruli $=2.12 \pm 0.34 \mathrm{mmHg} / \mathrm{s}, n=4)$, but they were proportionally larger ( $46 \%$ of glomerular responses) than with odor 
stimulation $(28 \%$ of glomerular responses). More importantly, the delay of $\mathrm{P}_{\text {tiss,O2 }}$ responses persisted to be shorter in glomeruli $(0.06 \pm 0.06 \mathrm{~s})$ than in the nerve layer $(0.43 \pm 0.06 \mathrm{~s})$ (Fig. $5 F)$.

Altogether, our results show that glomeruli are the main source of odor-evoked $\mathrm{P}_{\text {tiss,O2 }}$ decreases and that $\mathrm{P}_{\text {tiss, } \mathrm{O} 2}$ signals detected in the nerve layer mostly reflect "distant" glomerular oxygen consumption. This raises again the possibility that action potential propagation relies less on oxidative metabolism than postsynaptic activation. Could a difference in mitochondria density between ONL and GL layers support such hypothesis?

\section{Differential distribution of mitochondria in the glomerular and nerve layers}

Using electron microscopy, we assessed the density of mitochondria located in glomeruli and in the nerve layer from the medial aspect of the olfactory bulb (midway along the rostral caudal axis), using electron micrographs that totaled $19,375 \mu \mathrm{m}^{2}$ in the nerve layer and $15,300 \mu \mathrm{m}^{2}$ in glomeruli. From these two areas, $\sim 1500 \mu \mathrm{m}^{2}$ were randomly sampled using a $10 \mu \mathrm{m}^{2}$ mask/window. In the nerve layer, mitochondria density ranged from 0 to 21 per $10 \mu \mathrm{m}^{2}$ with a mean of $6.06 \pm 0.31$ (Fig. $6 A, B$ ). Importantly, the majority of mitochondria were observed in axons and only occasionally in the processes of the olfactory ensheathing cells. In the glomerular neuropil (Fig. 6C), the density of mitochondria ranged from 2 to 28 per $10 \mu \mathrm{m}^{2}$, with a mean of $13.08 \pm 0.34$, significantly higher than that found in the nerve layer. While the distribution of mitochondria in the dendritic processes and axonal terminals of the glomeruli appeared similar, there was a striking difference in the size of the dendritic mitochondria (compare Fig. 6A, $B$ with Fig. $6 C)$. Mitochondria in the dendritic processes were uniformly larger. This was not accounted for simply by the cross-sectional diameter of the dendrites since in longitudinal sections through the olfactory nerve layer (i.e., the oblique sections shown in Fig. $6 \mathrm{~B})$, the mitochondria were not particularly long. Moreover, the mean area of mitochondria in glomeruli was $15.61 \pm 2.83 \mu \mathrm{m}^{2}$ while it was $3 \pm 0.4 \mu \mathrm{m}^{2}$ in the nerve layer $(n=60$ mitochondria randomly chosen in each layer). Such differential distribution of mitochondria density and size has been well described in the monkey visual cortex (Wong-Riley, 1989; Wong-Riley et al., 1989). It supports the hypothesis that, in vivo, action potential propagation and postsynaptic depolarization may be associated with different weights of oxidative/glycolytic metabolism.

\section{Discussion}

Oxygen delivery in glomerular and nerve layers of the dorsal olfactory bulb

In the present work, we took advantage of the functional organization of the olfactory bulb to determine the relationship between capillary density and cellular subcompartment metabolism at a fine spatial resolution. Our 3D quantification of vascularity with TPLSM clearly indicates that the nerve layer barely contains any capillaries, although it contains ORN unmy-
C

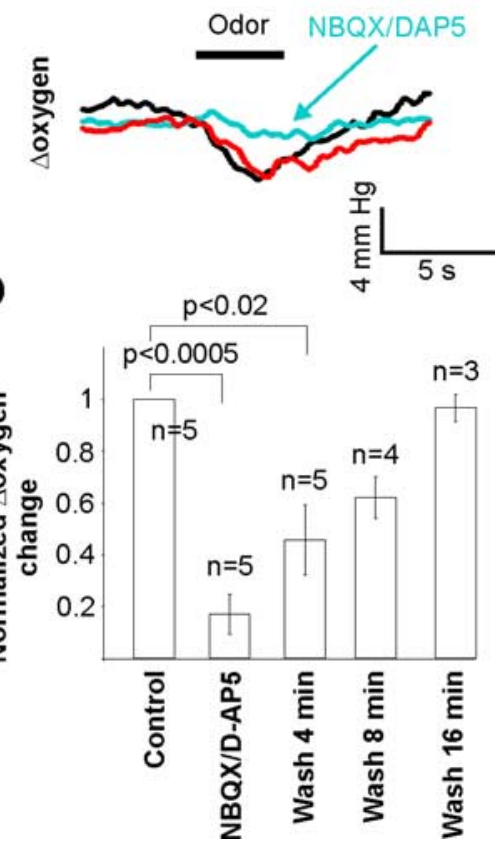

Figure 4. Oxygen consumption requires postsynaptic activation. $A$, Schematics. An LFP electrode containing $250 \mu \mathrm{m}$ NBQX and $500 \mu \mathrm{M}$ D-APV was placed near the oxygen sensor tip, within glomerular boundaries. $\boldsymbol{B}$, LFP negativities were reproducibly abolished by pressure application of glutamate antagonists. $C, D$, Glutamate antagonists strongly decreased or abolished oxygen responses. Measurements were performed $\sim 1$ min after drug application.

elinated axons and specialized glial cells such as microglial cells and glial ensheathing cells. Differences of vascularity within brain regions have been described long ago by Craigie (1920) and by Dunning and Wolff (1937) who both concluded that white matter was far more rich in capillaries than gray matter regions (for review, see Bär, 1980). In area 17 of the squirrel monkey (Zheng, 1991), capillary density is higher in blobs than in interblobs and much higher in layer IVc than in layer I (by a factor 3-4). However, these numbers are far from those we observed in the OB. In glomeruli, capillary density outnumbers that in the nerve layer by a factor $>10$. Moreover, with absolute capillary densities $>1000$ $\mathrm{mm} / \mathrm{mm}^{3}$, glomeruli from the dorsal $\mathrm{OB}$ appear to have the highest density reported in the brain. Whether this applies to all $\mathrm{OB}$ glomeruli that are known to show differences in size and input density (Schoenfeld and Knott, 2004) remains to be established. Could the high capillary density value result from the fact that each vessel acquired in $3 \mathrm{D}$ stacks was counted? It is improbable since the recent study by Weber et al. (2008) revealed that in the macaque visual cortex, absolute and ratio capillary values in and between layers IVc and I are still far from what we observed in the OB. Finally, in few extreme cases (data not shown), large volumes of nerve layer (e.g., within our $350 \times 350 \mu \mathrm{m}$ microscope field of view) overlying the glomeruli were even completely devoid of any kind of vessel. Thus, although arteries and arterioles, which are known to deliver a significant amount of oxygen to tissue by radial diffusion (Tsai et al., 2003), may participate in oxygenation of the nerve layer, we propose that oxygen is primarily delivered to glomeruli from where a large portion diffuses to the nerve layer and equilibrates at the glomerular $\mathrm{P}_{\text {tiss, } \mathrm{O} 2}$. The spatial distribution of the odor-evoked $\mathrm{P}_{\text {tiss, } \mathrm{O} 2}$ initial dip also supports this hypothesis. $\mathrm{P}_{\text {tiss, } \mathrm{O} 2}$ negativity recorded in the GL clearly preceded that recorded in the ONL. The fact that this delay persisted when using electrical stimulation of the olfactory nerve eliminates the 
A

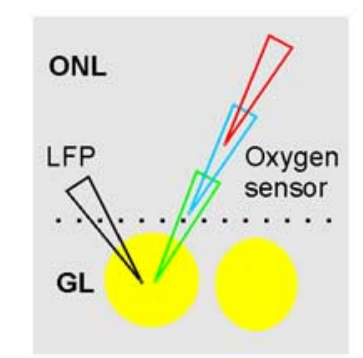

B

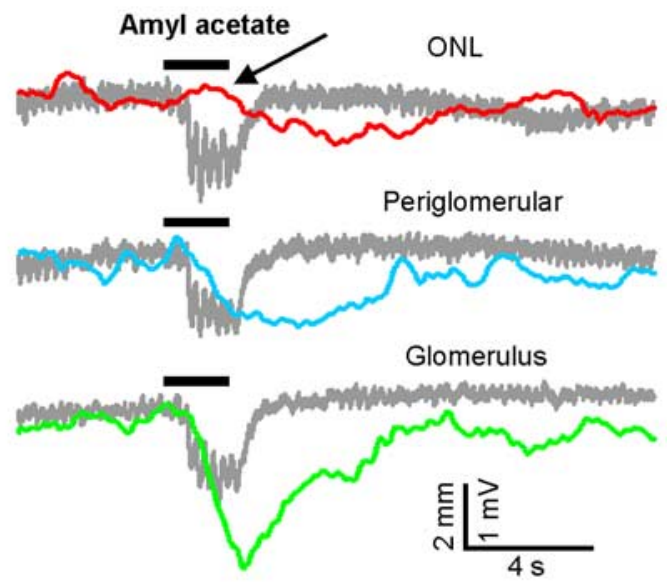

C
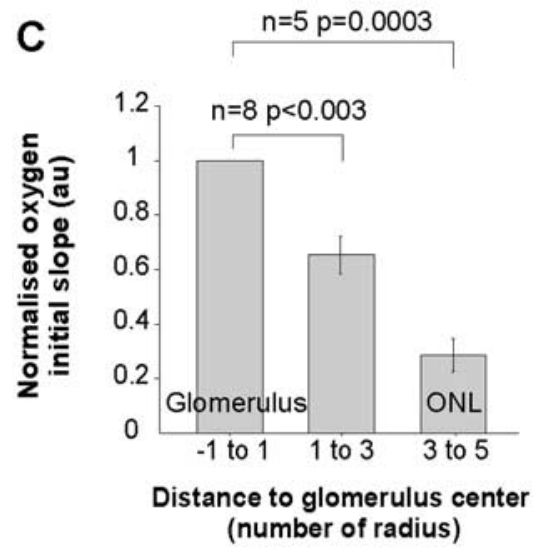

E

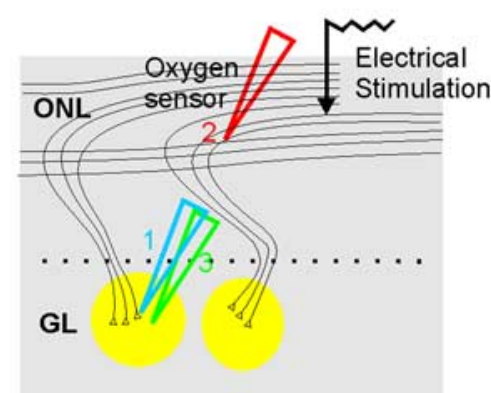

D

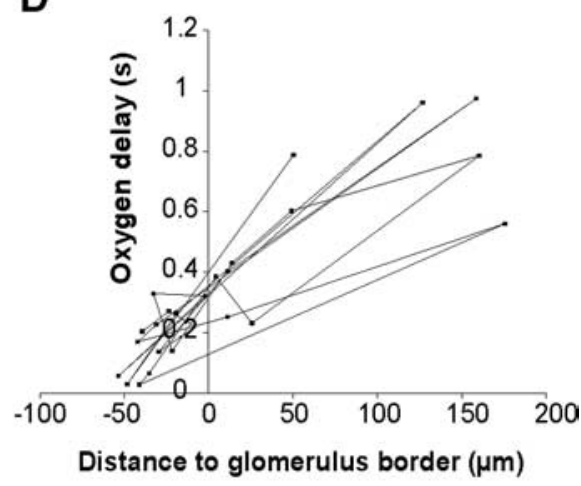

$\mathbf{F}$

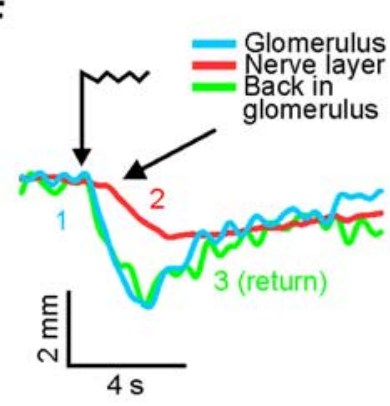

Figure 5. Contrasting odor-evoked $P_{\text {tiss, } 02}$ responses in the GL and ONL. $\boldsymbol{A}$, Schematics. The oxygen electrode was moved in different layers while maintaining LFP responses in the glomerulus. $\boldsymbol{B}, 0$ dor evokes a strong oxygen consumption in the glomerulus and a delayed and modest $P_{\text {tiss, } 02}$ response in the $0 N L$. LFP responses were maintained (gray traces). The arrow points to the beginning of the $P_{\text {tiss, } 02}$ response in the $0 N L$. C, Oxygen consumption statistics ( 8 rats). All $P_{\text {tiss, } 02}$ initial slope were normalized the glomerular response. Distance to the glomerulus center were normalized with the average glomerulus radius (average of maximal and minimal radius) to account for glomeruli variability in size. $D$, Delay between $L F P$ and $P_{\text {tiss, } 02}$ response onsets. $P_{\text {tiss, } 02}$ responses were always delayed in the $0 \mathrm{NL}$. The distance to the glomerular boundary was measured by assuming a spherical-like shape for the glomerulus, based on its average diameter. $\boldsymbol{E}$, Electrical stimulation of the $0 \mathrm{NL}$ similarly evoked a delayed $\mathrm{P}_{\text {tiss, } 02}$ response. Although a large portion of the $0 \mathrm{NL}$ was stimulated and the time for synaptic transmission bypassed, the $P_{\text {tiss, } 02}$ response was smaller and delayed in the $\mathrm{NL}$ compared with glomerular responses.

possibility that $\mathrm{P}_{\text {tiss, } \mathrm{O} 2}$ negativities in the nerve layer lagged the glomerular ones because the oxygen sensor was not placed at the site of activated axons. In our stimulation conditions (trains of strong shocks), a large portion of the dorsal nerve and glomerular layers were activated and the nerve oxygen response was still delayed while larger. Note that no additional and rapid (as in glomeruli) $\mathrm{P}_{\text {tiss, } \mathrm{O} 2}$ negativities appeared. Therefore, it is likely that $\mathrm{P}_{\text {tiss,O2 }}$ negativities observed in the ONL indirectly reflect oxygen consumed by glomerular processes. This question is discussed further below.

Oxygen consumption in glomeruli

During odor, activation of OSN terminals (Wachowiak et al., 2004) and postsynaptic responses (Chaigneau et al., 2007) are rather homogeneous within glomerular boundaries. It is thus not surprising that odor systematically induced decreases in $\mathrm{P}_{\text {tiss,O2 }}$ even though our sensor reported $\mathrm{P}_{\text {tiss,O2 }}$ only within a 2- to 6 - $\mu \mathrm{m}$-diameter sphere around the pipette tip. $\mathrm{P}_{\text {tiss, } \mathrm{O} 2}$ depends on both neuronal activity and CBF. Because even the early decreases in $\mathrm{P}_{\text {tiss, }} \mathrm{O} 2$ changes were partially masked by vascular inflow, we only considered the initial slope and not the integral or the amplitude of $\mathrm{P}_{\text {tiss,O2 }}$ decreases to demonstrate that oxygen is principally consumed by neuronal dendritic activation. We are aware that it is not possible to quantify, in absolute value, oxygen consumption without measuring oxygen released by hemoglobin. However, the initial slope of $\mathrm{P}_{\text {tiss, } \mathrm{O} 2}$ decreases can be used to compare oxygen consumption at a given site under two different pharmacological conditions (control and NBQX + $\mathrm{D}-\mathrm{APV}$ ), as long as the steady state CBF and $\mathrm{P}_{\text {tiss, } \mathrm{O} 2}$ do not change. We found that glutamate antagonists decreased by $>80 \%$ the $\mathrm{P}_{\text {tiss,O2 }}$ initial slope. Because these drugs enhance glutamate release (Petzold et al., 2008; Pírez and Wachowiak, 2008), they should also enhance the activation of metabotropic glutamate receptors and the uptake of glutamate by astrocytes. Therefore, our data indicate that firing of OSN terminals, enhanced release of glutamate and enhanced activation of astrocytes consume only $16 \%$ of the oxygen normally consumed during glomerular activation. The resting $84 \%$ correspond to oxygen required to restore ionic gradient of juxtaglomerular and mitral cell dendrites.

These percentages provide a new perspective on calculations of the glomerular energy budget (Nawroth et al., 2007) based on the energy demands of neuronal elements from the retina and the cortex. This theoretical study suggests that a third of total glomerular energy demands are due to axonal action potentials. If axonal demands are indeed of this order of magnitude, our results indicate that they are only partially met by aerobic metabolism. Alternatively, it is possible that oxygen consumption in the axonal compartments follows a slower time course than in the dendrites. It is an important consideration that different methods monitor different time courses of energy consumption and use different stimuli. For example, we only quantified what happens within the initial few hundred ms of odor responses (the initial slope of oxygen responses). In addition, our experiments were performed in anesthetized animals using odor stimulations lasting only 1-4 s. 


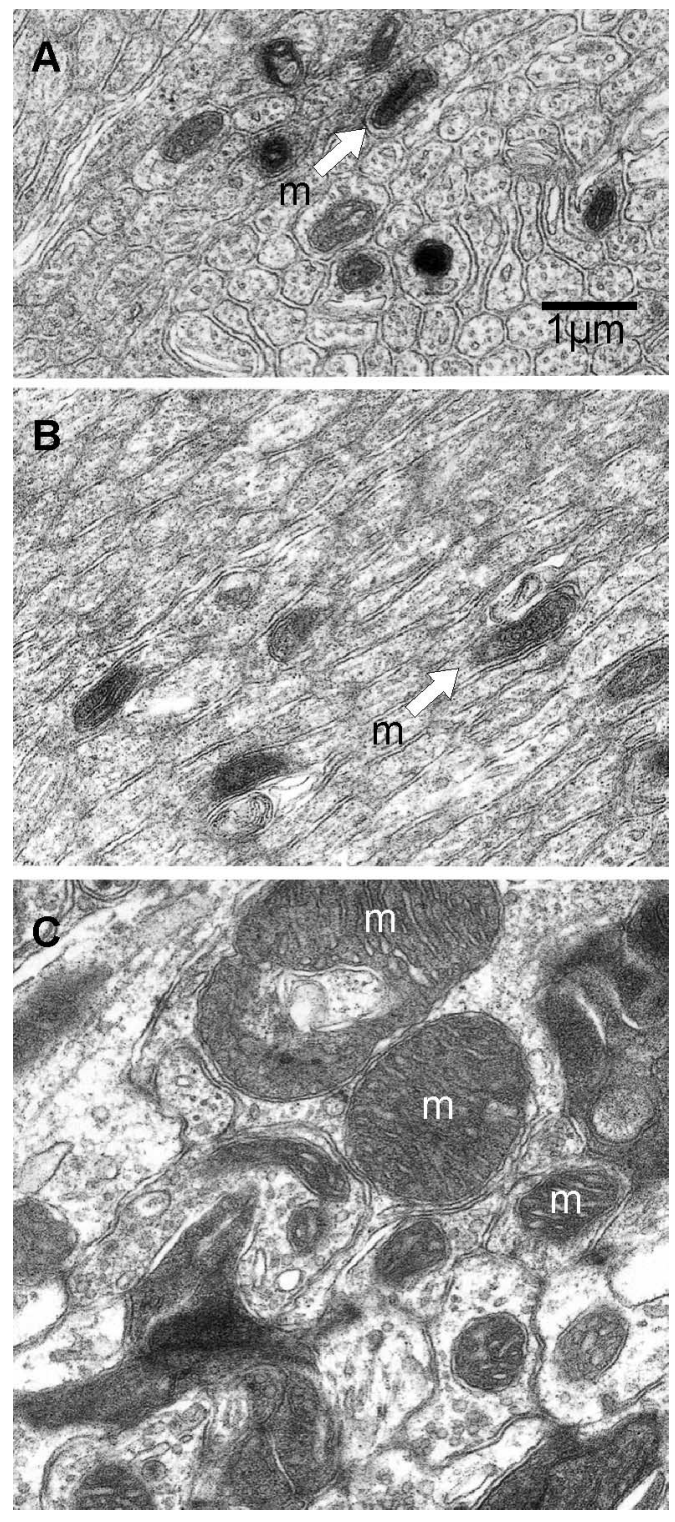

Figure 6. Electron micrographs illustrating the density and properties of mitochondria in the olfactory nerve layer and the glomerular neuropil. $\boldsymbol{A}$, Transverse section through an olfactory nerve fascicle shows many cross sections of the unmyelinated olfactory sensory neuron axons. Only nine mitochondria are seen (arrow). $\boldsymbol{B}$, Oblique section through the olfactory nerve showing semilongitudinally sectioned olfactory sensory axons. Note that the mitochondria do not conserve a larger volume by extending longitudinally within the axons, but rather maintain a small profile. C, Transverse section through the neuropil of a glomerulus. Many large mitochondria (i.e., $m$ ) are seen in the electron lucent dendrites. Electron dense olfactory sensory axon terminals are seen in the upper right and lower right. The scale bar for $\boldsymbol{A}-\boldsymbol{C}$ is shown in $\boldsymbol{A}$.

In contrast, 2-DG accumulation to odor stimulation (Sharp et al., 1977) and olfactory nerve stimulation (Greer et al., 1981) requires prolonged stimulation and occurs over a period of $45 \mathrm{~min}$, showing the highest levels of uptake in the olfactory glomeruli but also raised levels in the nerve layer. These high levels of 2-DG in the nerve layer may therefore register the slow diffusion of oxygen from glomerular capillaries and the slow metabolism occurring in the mitochondria of the nerve layer (see the discussion on 2-DG limitations in (Johnson and Leon, 2007)). Similarly, studies of the BOLD signal with odor stimulation periods of $30 \mathrm{~s}$ and show the highest BOLD signal in the glomeruli, with also raised levels in the ONL (Kida et al., 2002). Thus, different methods appear to give critical insights into the time courses of oxygen and glucose diffusion from the glomeruli and rates of energy metabolism in the different layers.

These results also confirm the dendritic origin of oxygen consumption reported in the cerebellar cortex upon electrical stimulation (Offenhauser et al., 2005), in good accordance with the dendritic distribution of cytochrome $c$ enzyme expression (Borowsky and Collins, 1989). Are they at odds with the mechanisms for blood flow regulation? Two hypotheses have been proposed for the regulation of neurovascular coupling. In the first scheme, glutamate released by excitatory afferents activates astrocytes, which then trigger the vascular response (Gurden et al., 2006; Petzold et al., 2008). In the second scheme, postsynaptic activation of neurons is required (Mathiesen et al., 1998; Yang and Iadecola, 1998; Chaigneau et al., 2007; Tiret et al., 2009). We believe that the differential weight of the two schemes (astrocyte vs neurons) remains to be established and may depend on the level of activity (Shepherd and Charpak, 2008). Note that in the "astrocyte" hypothesis, oxygen consumption and neurovascular coupling would involve different cellular compartments.

\section{Energy consumption by action potential propagation}

Our results also indicate that little oxygen is consumed during action potential propagation. Could action potential propagation then use ATP produced by an anaerobic metabolism? It seems to be the case for a subpopulation of axons of the optic nerve and the corpus callosum (Fern et al., 1998; Tekkök et al., 2003; Tekkök and Ransom, 2004), which are particularly resistant to anoxia but not to aglycemic anoxia. In the OB, this hypothesis is supported by the distribution of cytochrome $c$ oxidase, which is absent from the nerve layer and the periglomerular region, while it is highly concentrated in the glomerular neuropil (Borowsky and Collins, 1989; Hevner and Wong-Riley, 1989). Also, mitochondria density was lower $(\sim 50 \%)$ and mitochondria size much smaller in the nerve layer than in glomeruli. Although measured in medial OB, our mitochondria counts should apply to the entire $\mathrm{OB}$ since ONL thickness is always proportional to the size of glomeruli (unpublished results). Also, mitochondria density was lower $(\sim 50 \%)$ and mitochondria size smaller in the nerve layer than in glomeruli. Such difference has already been reported in other brain regions (Wong-Riley, 1989) and in our case, the difference in mitochondrial count is smaller than what exists between axonal terminals $(\sim 15 \%)$ or myelinated axons $(<10 \%)$ and dendrites from the visual cortex (Wong-Riley et al., 1989). Thus, although it is difficult to infer anything quantitative about ATP metabolism from our mitochondrial observation, we believe that the differential distribution of mitochondria supports the hypothesis that action potential propagation and postsynaptic depolarization may be associated with differences in metabolism. We hypothesize that in glomeruli, ATP is produced through oxidative metabolism, whereas in the nerve layer, ATP immediate energy requirements are produced through glycolysis, though not excluding the restitution of ionic equilibrium through slower aerobic processes. The dominant role of glycolysis in axonal excitability would explain the general difference in white and gray matter metabolism, as deduced from 2-DG experiments and cytochrome oxidase histocytochemistry: the 12-fold increase in cytochrome oxidase activity from white to gray (Hevner et al., 1995) matter is only associated with a threefold increase in glucose consumption (Sokoloff et al., 1977).

We emphasize that these results may be specific to the organization of the superficial layers of the olfactory bulb, with respect to two special attributes: the high density of unmyelinated axons in the olfactory nerve layer and the high density of synaptic 
terminals in the glomeruli. Further experiments will be required to determine the extent to which the mechanisms revealed by the present experiments apply to other well studied regions such as the retina and the cerebral cortex.

\section{References}

Attwell D, Laughlin SB (2001) An energy budget for signaling in the grey matter of the brain. J Cereb Blood Flow Metab 21:1133-1145.

Bär T (1980) The vascular system of the cerebral cortex. Adv Anat Embryol Cell Biol 59:I-VI, 1-62.

Borowsky IW, Collins RC (1989) Metabolic anatomy of brain: a comparison of regional capillary density, glucose metabolism, and enzyme activities. J Comp Neurol 288:401-413.

Brickley SG, Farrant M, Swanson GT, Cull-Candy SG (2001) CNQX increases GABA-mediated synaptic transmission in the cerebellum by an AMPA/kainate receptor-independent mechanism. Neuropharmacology 41:730-736.

Caesar K, Offenhauser N, Lauritzen M (2008) Gamma-aminobutyric acid modulates local brain oxygen consumption and blood flow in rat cerebellar cortex. J Cereb Blood Flow Metab 28:906-915.

Chaigneau E, Oheim M, Audinat E, Charpak S (2003) Two-photon imaging of capillary blood flow in olfactory bulb glomeruli. Proc Natl Acad Sci U S A 100:13081-13086.

Chaigneau E, Tiret P, Lecoq J, Ducros M, Knöpfel T, Charpak S (2007) The relationship between blood flow and neuronal activity in the rodent olfactory bulb. J Neurosci 27:6452-6460.

Craigie EH (1920) On the relative vascularity of various parts of the central nervous system of the albino rat. J Comp Neurol 31:429-464.

Deschamps T, Cohen LD (2001) Fast extraction of minimal paths in 3D images and applications to virtual endoscopy. Med Image Anal 5:281-299.

Dunning HS, Wolff HG (1937) The relative vascularity of various parts of the central and peripheral nervous system of the cat and its relation to function. J Comp Neurol 67:433-450.

Fern R, Davis P, Waxman SG, Ransom BR (1998) Axon conduction and survival in CNS white matter during energy deprivation: a developmental study. J Neurophysiol 79:95-105.

Greer CA, Mori K, Shepherd GM (1981) Localization of synaptic responses in the in vitro turtle olfactory bulb using the [14C]2-deoxyglucose method. Brain Res 217:295-303.

Gundersen JK, Ramsing NB, Glud RN (1998) Predicting the signal of O2 microsensors from physical dimensions, temperature, salinity, and $\mathrm{O} 2$ concentration. Limnol Oceanogr 43:1932-1937.

Gurden H, Uchida N, Mainen ZF (2006) Sensory-evoked intrinsic optical signals in the olfactory bulb are coupled to glutamate release and uptake. Neuron 52:335-345.

Hevner RF, Wong-Riley MT (1989) Brain cytochrome oxidase: purification, antibody production, and immunohistochemical/histochemical correlations in the CNS. J Neurosci 9:3884-3898.

Hevner RF, Liu S, Wong-Riley MT (1995) A metabolic map of cytochrome oxidase in the rat brain: histochemical, densitometric and biochemical studies. Neuroscience 65:313-342.

Johnson BA, Leon M (2007) Chemotopic odorant coding in a mammalian olfactory system. J Comp Neurol 503:1-34.

Kasowski HJ, Kim H, Greer CA (1999) Compartmental organization of the olfactory bulb glomerulus. J Comp Neurol 407:261-274.

Kida I, Xu F, Shulman RG, Hyder F (2002) Mapping at glomerular resolution: fMRI of rat olfactory bulb. Magn Reson Med 48:570-576.

Kleinfeld D, Mitra PP, Helmchen F, Denk W (1998) Fluctuations and stimulusinduced changes in blood flow observed in individual capillaries in layers 2 through 4 of rat neocortex. Proc Natl Acad Sci U S A 95:15741-15746.

Mathiesen C, Caesar K, Akgören N, Lauritzen M (1998) Modification of activity-dependent increases of cerebral blood flow by excitatory synaptic activity and spikes in rat cerebellar cortex. J Physiol 512:555-566.

Nawroth JC, Greer CA, Chen WR, Laughlin SB, Shepherd GM (2007) An energy budget for the olfactory glomerulus. J Neurosci 27:9790-9800.

Ndubuizu O, LaManna JC (2007) Brain tissue oxygen concentration measurements. Antioxid Redox Signal 9:1207-1219.

Offenhauser N, Thomsen K, Caesar K, Lauritzen M (2005) Activity-induced tissue oxygenation changes in rat cerebellar cortex: interplay of postsynaptic activation and blood flow. J Physiol 565:279-294.

Petzold GC, Albeanu DF, Sato TF, Murthy VN (2008) Coupling of neural activity to blood flow in olfactory glomeruli is mediated by astrocytic pathways. Neuron 58:897-910.
Pírez N, Wachowiak M (2008) In vivo modulation of sensory input to the olfactory bulb by tonic and activity-dependent presynaptic inhibition of receptor neurons. J Neurosci 28:6360-6371.

Schafer JR, Kida I, Rothman DL, Hyder F, Xu F (2005) Adaptation in the rodent olfactory bulb measured by fMRI. Magn Reson Med 54:443-448.

Schoenfeld TA, Knott TK (2004) Evidence for the disproportionate mapping of olfactory airspace onto the main olfactory bulb of the hamster. J Comp Neurol 476:186-201.

Sethian JA (1999) Efficient schemes: fast marching methods. In: Level set methods and fast marching methods (Ciarlet PG, Iserles A, Kohn RV, Wright MH, eds), pp 86-99. Cambridge, UK: Cambridge UP.

Sharp FR, Kauer JS, Shepherd GM (1975) Local sites of activity-related glucose metabolism in rat olfactory bulb during olfactory stimulation. Brain Res 98:596-600.

Sharp FR, Kauer JS, Shepherd GM (1977) Laminar analysis of 2-deoxyglucose uptake in olfactory bulb and olfactory cortex of rabbit and rat. J Neurophysiol 40:800-813.

Shepherd GM (2003) The single capillary and the active brain. Proc Natl Acad Sci U S A 100:12535-12536.

Shepherd GM, Charpak S (2008) The olfactory glomerulus: a model for neuro-glio-vascular biology. Neuron 58:827-829.

Shepherd GM, Chen WR, Greer CA (2004) Olfactory bulb. In: The synaptic organization of the brain (Shepherd GM, ed), pp 165-216. New York: Oxford UP.

Sokoloff L, Reivich M, Kennedy C, Des Rosiers MH, Patlak CS, Pettigrew KD, Sakurada O, Shinohara M (1977) The [14C]deoxyglucose method for the measurement of local cerebral glucose utilization: theory, procedure, and normal values in the conscious and anesthetized albino rat. J Neurochem 28:897-916.

Tekkök SB, Ransom BR (2004) Anoxia effects on CNS function and survival: regional differences. Neurochem Res 29:2163-2169.

Tekkök SB, Brown AM, Ransom BR (2003) Axon function persists during anoxia in mammalian white matter. J Cereb Blood Flow Metab 23:1340-1347.

Thompson JK, Peterson MR, Freeman RD (2003) Single-neuron activity and tissue oxygenation in the cerebral cortex. Science 299:1070-1072.

Thompson JK, Peterson MR, Freeman RD (2004) High-resolution neurometabolic coupling revealed by focal activation of visual neurons. Nat Neurosci 7:919-920.

Thompson JK, Peterson MR, Freeman RD (2005) Separate spatial scales determine neural activity-dependent changes in tissue oxygen within central visual pathways. J Neurosci 25:9046-9058.

Tiret P, Chaigneau E, Lecoq J, Charpak S (2009) Two-photon imaging of capillary blood flow in olfactory bulb glomeruli. Methods Mol Biol 489:81-91.

Tsai AG, Friesenecker B, Mazzoni MC, Kerger H, Buerk DG, Johnson PC, Intaglietta M (1998) Microvascular and tissue oxygen gradients in the rat mesentery. Proc Natl Acad Sci U S A 95:6590-6595.

Tsai AG, Johnson PC, Intaglietta M (2003) Oxygen gradients in the microcirculation. Physiol Rev 83:933-963.

Wachowiak M, Cohen LB (2001) Representation of odorants by receptor neuron input to the mouse olfactory bulb. Neuron 32:723-735.

Wachowiak M, Denk W, Friedrich RW (2004) Functional organization of sensory input to the olfactory bulb glomerulus analyzed by two-photon calcium imaging. Proc Natl Acad Sci U S A 101:9097-9102.

Weber B, Keller AL, Reichold J, Logothetis NK (2008) The microvascular system of the striate and extrastriate visual cortex of the macaque. Cereb Cortex 18:2318-2330.

Wong-Riley MT (1989) Cytochrome oxidase: an endogenous metabolic marker for neuronal activity. Trends Neurosci 12:94-101.

Wong-Riley MT, Trusk TC, Tripathi SC, Hoppe DA (1989) Effect of retinal impulse blockage on cytochrome oxidase-rich zones in the macaque striate cortex: II. Quantitative electron-microscopic (EM) analysis of neuropil. Vis Neurosci 2:499-514.

Xu F, Kida I, Hyder F, Shulman RG (2000) Assessment and discrimination of odor stimuli in rat olfactory bulb by dynamic functional MRI. Proc Natl Acad Sci U S A 97:10601-10606.

Yang G, Iadecola C (1998) Activation of cerebellar climbing fibers increases cerebellar blood flow: role of glutamate receptors, nitric oxide, and cGMP. Stroke 29:499-507; discussion 507-508.

Zheng D, LaMantia AS, Purves D (1991) Specialized vascularization of the primate visual cortex. J Neurosci 11:2622-2629. 